\title{
Teachers' Perspectives on Factors Affecting EFL Learners' Course Learning Outcomes: A Case Study
}

\author{
Mansoor S. Almalki, PhD \\ English Language Centre, Deanship of Supportive Studies, \\ Taif University, P. O. Box 888, Taif 21974, Saudi Arabia.
}

\begin{abstract}
This study analyses EFL teachers' perceptions regarding factors that impact the low or high attainment of students' Course Learning Outcomes (CLOs). Using a detailed questionnaire to collect the related data from 138 teachers, who teach Regular English for Academic Purposes (REAP) and Intensive English for Academic Purposes (IEAP), the research paper asks teachers to provide their viewpoint on various factors such as teaching material in the form of books, supplementary material such as the online resources, students' interest, teachers' training on targeting their teaching to achieve the related CLOs, textbook exercises and time constraints to measure their impact on the actual attainment of the CLOs. The study is important as the respondents of the questionnaire are teachers who teach either REAP that expands over a period of four continuous semesters (two years) or IEAP that covers the same course in two semesters (one year). The study has been carried out in a way that the REAP and IEAP respondents of the questionnaire have been placed in two separate groups, adding another dimension for prospective researchers to the research in terms of evaluating how the time factor influences, either negatively or positively, the attainment of the students' CLOs.
\end{abstract}

Keywords: Course Learning Outcomes, EFL Context, Outcome-based Education, Teachers' Perceptions

\section{INTRODUCTION}

The recent globalized harmonization of study models and educational structures (Lucena et al. 2008; Brennan, Patel, and Tang 2009), causing a profound programmatic as well as structural paradigm shift in higher education, have given rise to questions on the contextual validity and efficacy of modelling and measuring learning outcomes in English language teaching (McLean, 2018). Left unattended, the presence of uncongenial environment exacerbates the anxiety level of a second language learner (Horwitz, 2016; Oxford, 2017; Rodriguez, 2017). Almalki (2014) highlights that measurable learning outcomes as well as efficient assessment designs need policies revision as well as consistent reviews of institutions' guidelines. The same goes for the evaluation of Course Learning Outcome (CLOs) to be tested in any given context to ensure that all the CLOs for any given course are measureable as well as considerably representative of students' overall attainment in that particular course.

\section{RATIONALE FOR THE CURRENT STUDY}

The rationale behind authenticity is that the volitional, affective motivational, cognitive and social dispositions, which combine to form competencies, provide the basis for performance in a TESOL assessment and beyond. Thus, while assessing the learning outcomes, the contextual variables of the aforementioned basis for performance need to be taken into consideration in a bid to ensure a valid assessment (Zlatkin-Troitschanskaia, Shavelson, and Kuhn, 2015) and avoid using a discordant yardstick.

Students' attainment of their Course Learning Outcomes (CLOs) plays a crucial role in measuring their success in any particular course. This attainment is ensured by teachers 
through not only classroom teaching but also by encouraging teamwork, providing prompt feedback, in and out of the classroom feedback and a consistently improving teaching material (Schoepp, 2019; Hadjianastasis, 2017; Scott et al., 2010). Other than providing prompt feedback to students, effective teachers take measures to make their students into critical thinkers by motivating them towards active learning (Hammer et al., 2010). In addition to paying keen heed to the curriculum related issues, effective teachers are charismatic, zealous towards their profession, respectful and culturally sensitive (Paolini, 2015). The modus operandi of such teachers is that they set high yet realistic expectations of their students, encouraging them to ask questions to generate discussions of the higher thinking order and stimulate open communication. The secret of their successful journey lies in their efforts for continuous improvement through hard work and dedication. Hammer et al., (2010) assert that teachers' improvement depend considerably on the effective self-reflection and self-evaluation pertaining to their performance.

\section{CONTEXT OF THE STUDY}

As a matter of fact, Taif University English Language Centre caters for teaching courses such as Regular English for Academic Purposes (REAP), Intensive English for Academic Purposes (IEAP), and a host of English for Specific Purposes (ESP) courses for various disciplines such as engineering medicine and pharmacy etc. Being home to over 250 male and female teachers, with educational qualifications ranging from Masters to $\mathrm{PhD}$, there has always been the need to evolve a quantifiably effective assessment approach towards measuring the effectiveness of CLOs that is uniformly applied through the operations of the Centre, impacting a large number of students.

Among the over 250 teachers, there are around 150 EFL teachers, who teach Regular English for Academic Purposes (REAP) and Intensive English for Academic Purposes (IEAP) at Taif University English Language Centre. Some of them teach ESP courses, however the majority of teachers teach REAP and IEAP courses. Before introducing new English course, the teachers were provided orientation sessions as well as necessary training on how to teach new course by the publishers (Cambridge University Press). The study is important as the respondents of the questionnaire are teachers who teach either REAP that expands over a period of four continuous semesters (two years) and IEAP that covers the same course in two semesters (one year). The study has been carried out in a way that the REAP and IEAP respondents of the questionnaire have been place in two separate groups, adding another dimension to the research in terms of evaluating how the time factor influences, either negatively or positively, the attainment of the students' CLOs.

\section{OBJECTIVES OF THE STUDY}

The main objective of the study is to find out teachers' perception about the attainment of CLOs in terms of what factors are responsible for either the low or high attainment of these CLOs as measured through the performance of the students.

\section{RESEARCH QUESTIONS}

The study endeavors to answer the following research questions:

1. What are the factors responsible for the high or low attainment of CLOs, as measured through the students' performance in an EFL classroom?

2. In what ways do the perspectives of IEAP and REAP teachers differ from one another in terms of their view on the reasons responsible for the either high or low attainment of CLOs? 


\section{RESEARCH DESIGN, FINDINGS AND DISCUSSION}

Eksi et al. (2019) emphasize the importance of teachers' perspectives on ways to achieve CLOs. The whole process that leads towards the final attainment of CLOs involves a well though-out mechanism that must include the efficient heed to the viewpoints of teachers (Khorvash \& Lotfi, 2019). For the current study, the related data was collected from REAP and IEAP teachers. A questionnaire was developed and sent to teachers after proper piloting. The questionnaire included a number of variables, asking the teachers to give their opinion on the reasons responsible for either low or high attainment of students' CLOs. Of the total 150 teachers, who teach either IEAP or REAP, 138 teachers completed the online questionnaire. Out of this total number, 107 (77\%) teachers teach Regular English for Academic Purposes (REAP) and 26 (19\%) teach Intensive English for Academic Purposes (IEAP). 60\% of all teachers are aged between $23-35 ; 63 \%$ are aged between $36-40 ; 63 \%$ are aged between $41-50$ and $14 \%$ are aged between 51-60. The majority of teachers (65\% REAP and 54\% IEAP) have BA and MA degrees in applied linguistics, English language teaching, TESOL, etc.

In general, REAP and IEAP teachers have similar teaching experiences in years with the only difference that there are more new REAP teachers (14\% with a teaching experience between 1-3 years) compared to IEAP (4\% of teachers with a teaching experience between 1-3 years). The majority of IEAP teachers have 9-15 years of teaching experience compared to REAP teachers where the majority have 16-20 years of teaching experience.

\section{The Role of Textbooks in Achievement of CLOs}

Teachers' perceptions on the role of textbooks can hardly be emphasized when it comes to achieving the learning outcomes (Panezai and Channa, 2017; Oolbekkink-Marchand, Driel \& Verloop, 2014). In the same vein, when asked about the role of textbooks as well as their efficacy towards achieving the CLOs, the respondents, in general, both REAP and IEAP teachers, think that the textbooks are appropriate for the students' levels (80\% REAP; 73\% IEAP). With regard to the importance of learning English for students, 78\% REAP and 73\% IEAP teachers think that learning English is important to their students. The following figure 1 and 2 provide the details of the perspectives of REAP and IEAP teachers:
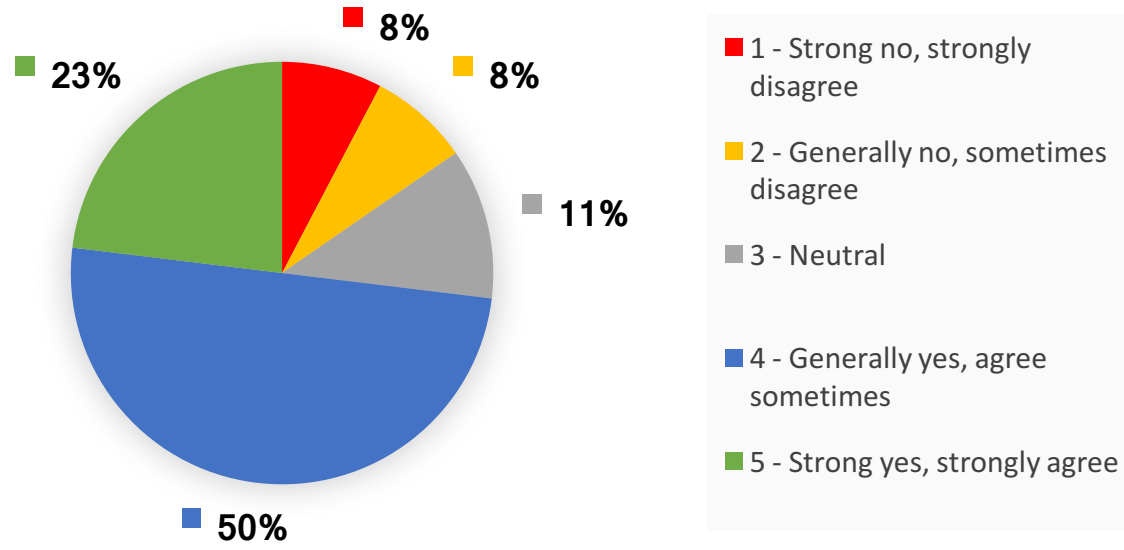

Figure 1: IEAP Teachers' Perspectives on Textbooks 

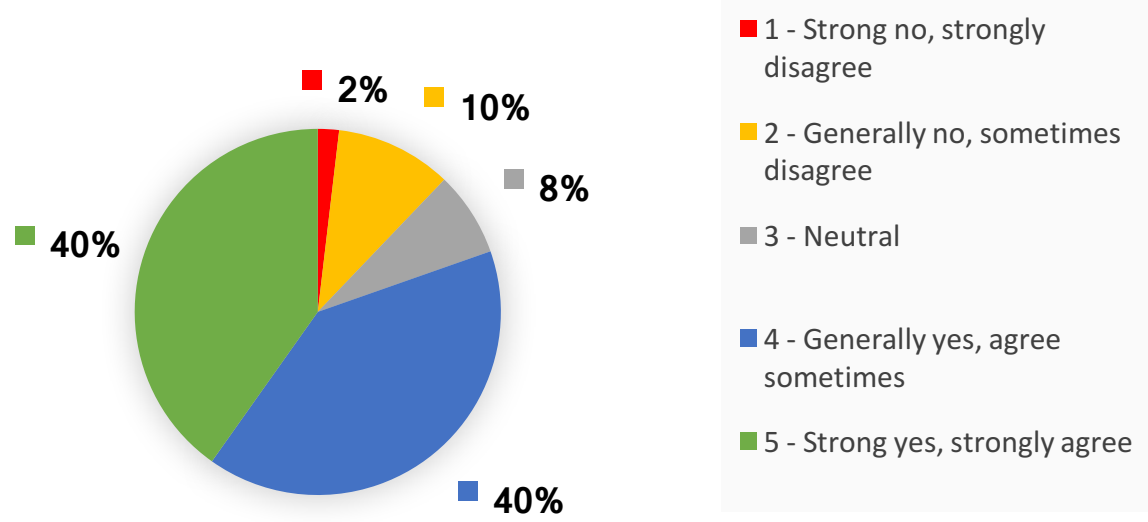

Figure 2: REAP Teachers' Perspectives on Textbooks

\section{The importance of framing CLOs}

There is no denying the fact the way CLOs are framed needs to be well understood in a bid to avoid any future problems (Schoepp, 2019; Liang et al., 2018; Ling-Yee, 2011). With regard to the importance of how the CLOs are framed, in terms of how measureable and achievable they are in learning English, 78\% REAP and 73\% IEAP teachers think that the framing of CLOs is equally important. The following figure 3 and 4 provide the details of the perspectives of REAP and IEAP teachers:

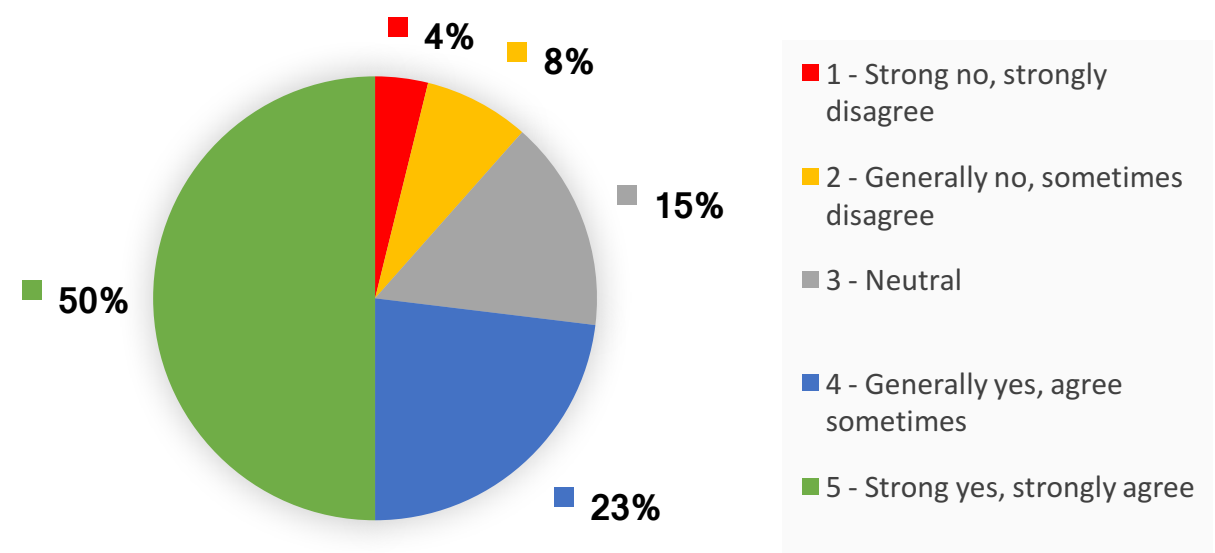

Figure 3: IEAP Teachers' Perspective on Importance of CLOs
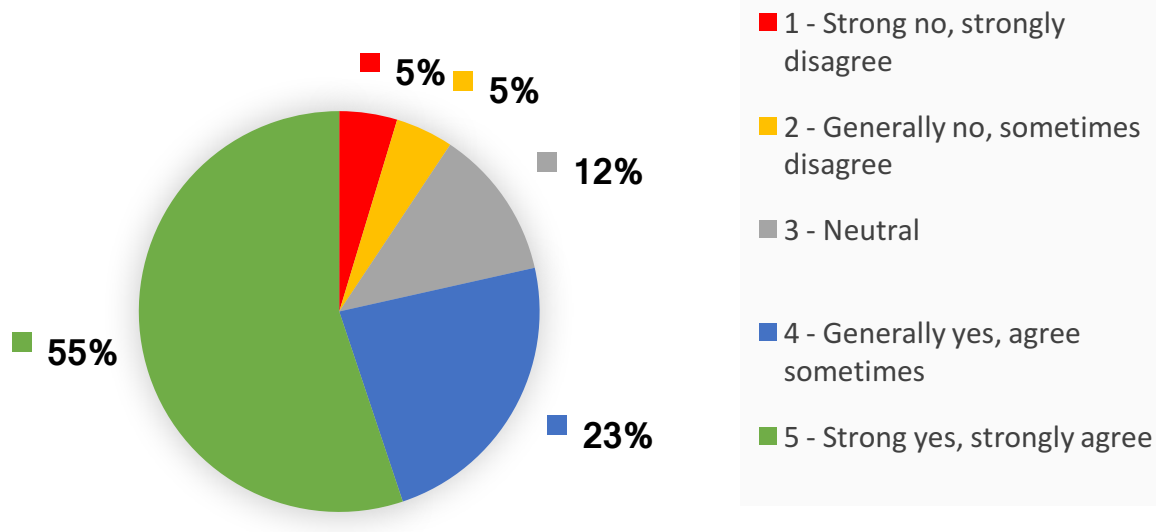

Figure 4: REAP Teachers' Perspective on Importance of CLOs 


\section{CLOs and Learning English}

Hung (2019) emphasizes the role of EFL learners' motivation as a key factor towards achieving the CLOs. Sheybani and Miri (2019) assert that the learners' motives behind their endeavours to learn English may lead the teachers to tailor the teaching process towards the maximum attainment of the learning goals. Teachers think that there are multiple reasons why the students took the English Unlimited course. Many teachers think this is because English is a major/minor requirement (32\% REAP; 27\% IEAP) closely followed by teachers who think that the students need English for their future jobs (28\% REAP; 23 IEAP) and because English is general education (20\% REAP; 19\% IEAP). The following figure 5 and 6 provide the details of the perspectives of REAP and IEAP teachers:

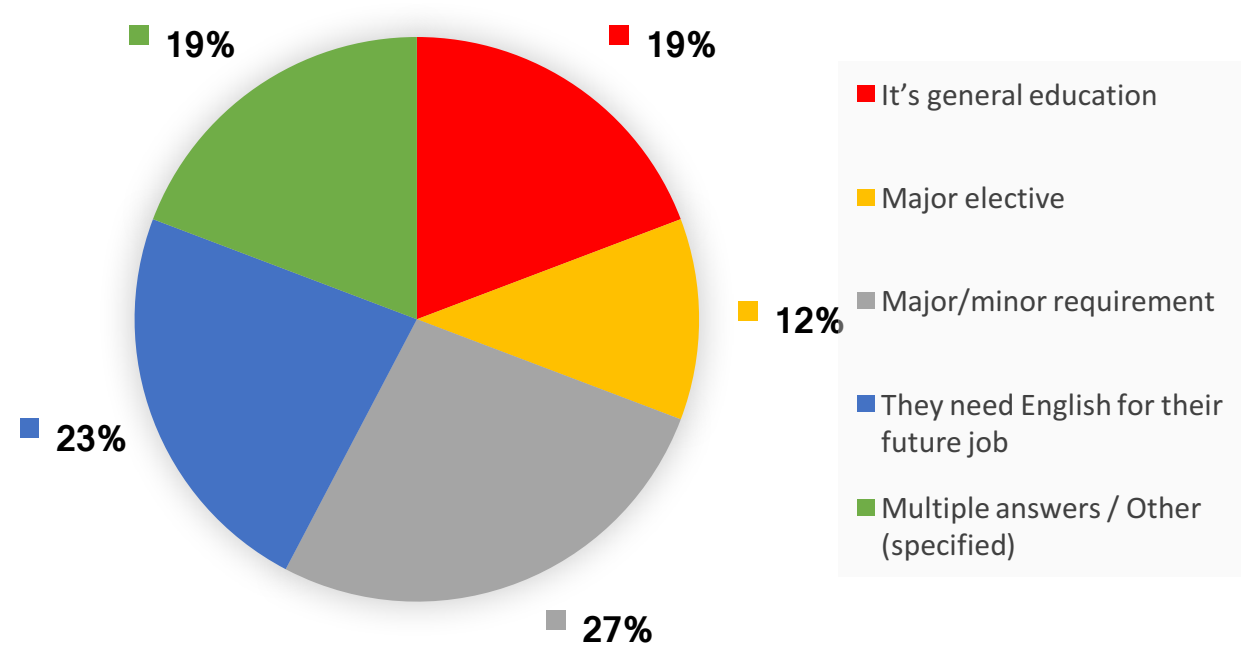

Figure 5: IEAP Teachers' Perspectives of CLOs and Learning English

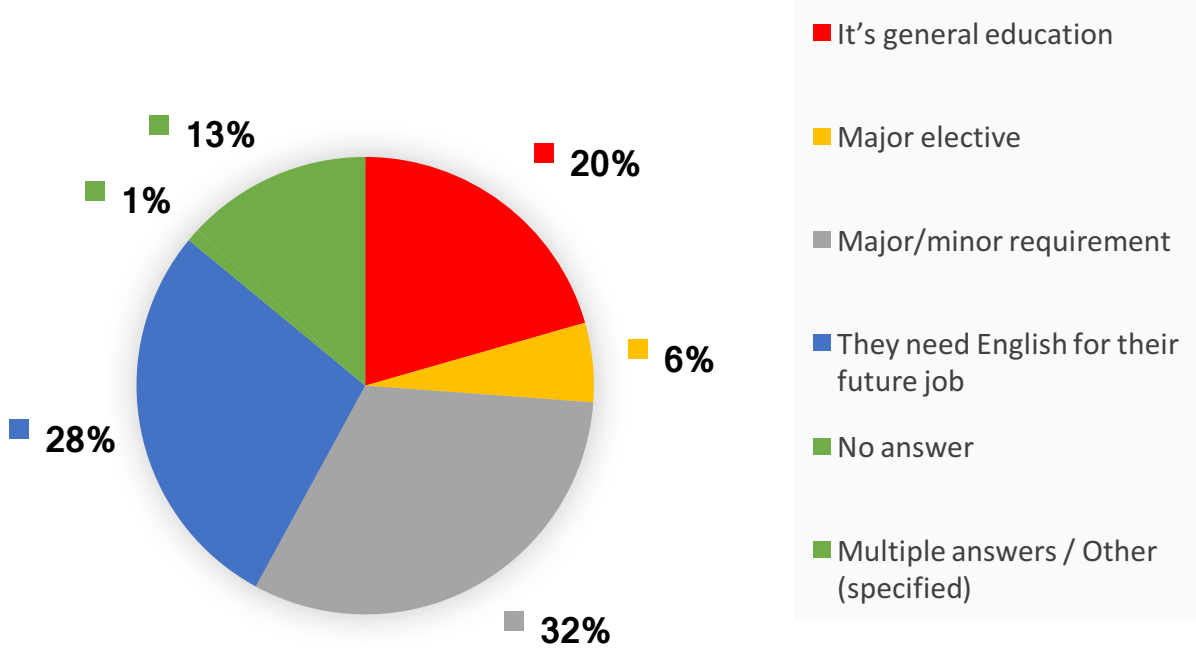

Figure 6: REAP Teachers Perspectives of CLOs and Learning English

\section{CLOs and Teaching Content}

The role of the teaching content is vital in the achievement of CLOs (Tohidian \& Rahimian, 2019). When asked about what element in classroom teaching could improve the overall attainment of CLOs, the teachers thought there were multiple reasons with 32\% REAP and $38 \%$ IEAP teachers who think it is because of the interesting topics and reading/listening texts, practice activities (24\% REAP; 19\% IEAP) and conversational English (17\% REAP; 31\% IEAP). 
Teachers are divided as to how much time their students spend studying for the English Unlimited course outside the class. The majority of teachers (35\% REAP; 38\% IEAP) think their students spend two hours a week studying for the English Unlimited course outside the class. Also, 32\% of REAP and 23\% IEAP teachers said that their students spend three hours a week studying outside the class. This is unexpected having in mind that IEAP students have 6 hours of English language classes per week compared to 3 hours per week for REAP students. The following figure 7 and 8 provide the details of the perspectives of REAP and IEAP teachers:

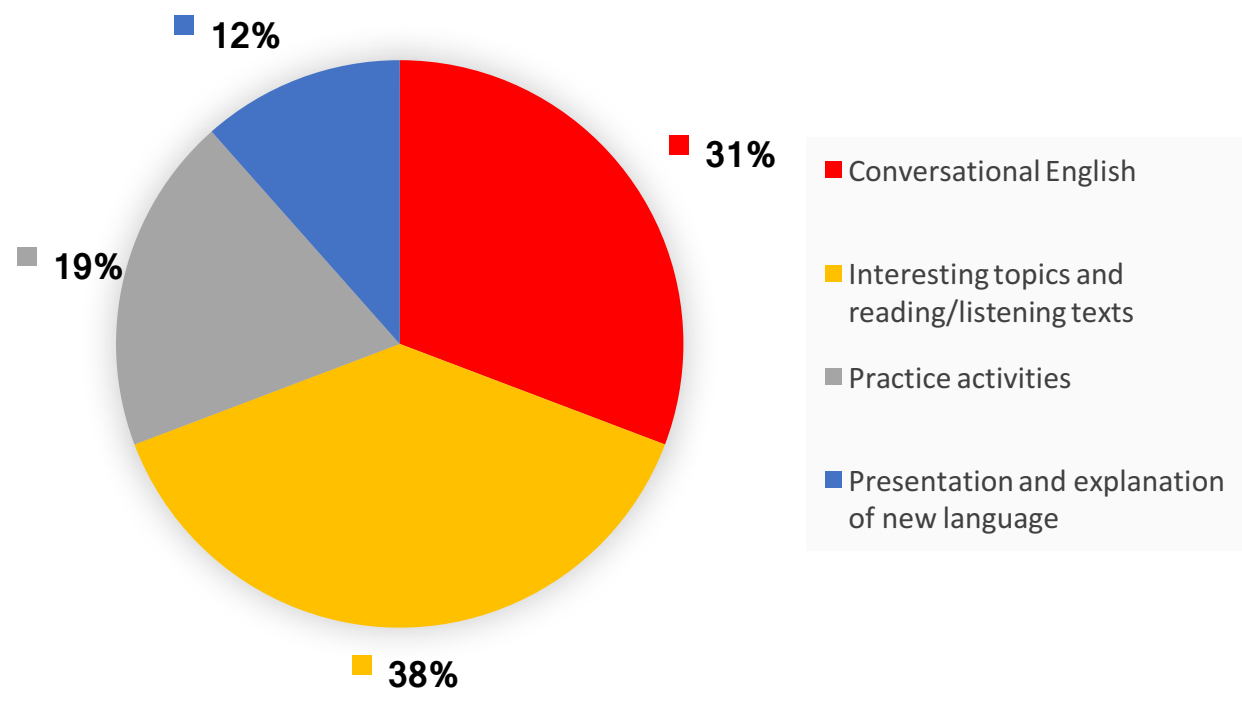

Figure 7: IEAP Teachers Perspectives on Teaching Content

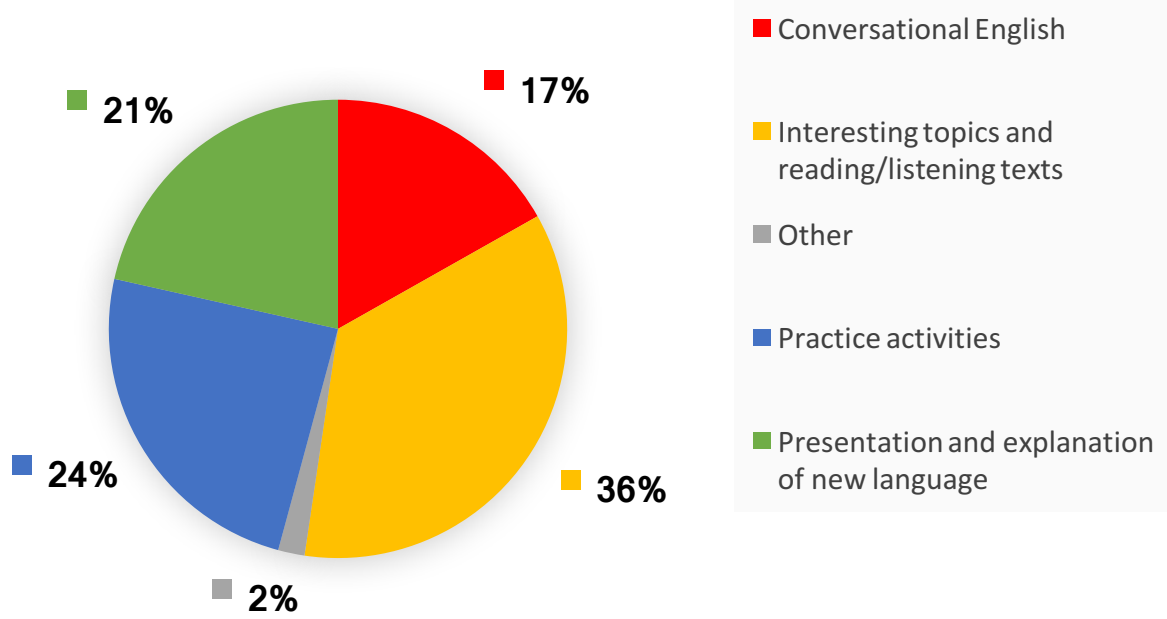

Figure 8: REAP Teachers Perspectives on Teaching Content

\section{Reasons for Low Attainment of CLOs}

When asked about the reasons for students' lack of interest in classroom teaching that leads to low attainment of CLOs, the teachers seemed to be divided about what the students liked the least about the course. Some teachers think that there was not enough explanation $16 \%$ REAP; 31\% IEAP) followed by teachers who thought that there was not enough practice (24\% REAP; 19\% IEAP). Other teachers think that the topics and texts were not interesting enough (9\% REAP; 19\% IEAP) or they provided multiple reasons and/or other (26\% REAP; $15 \%$ IEAP). Interestingly, there is some difference between REAP and IEAP teachers with regard to whether the course was too hard/too easy. 17\% of REAP teachers think that the course was too hard but only $4 \%$ of IEAP teachers claimed this to be the case. By contrast, most of the IEAP 
teachers said that the course was too easy (12\%) compared to only $8 \%$ of REAP teachers. As above, Hargreaves, Elhawary and Mahgoub (2019) also hold that the reasons behind the low attainment of CLOs can be varying in nature. The following figure 9 and 10 provide the details of the perspectives of REAP and IEAP teachers:

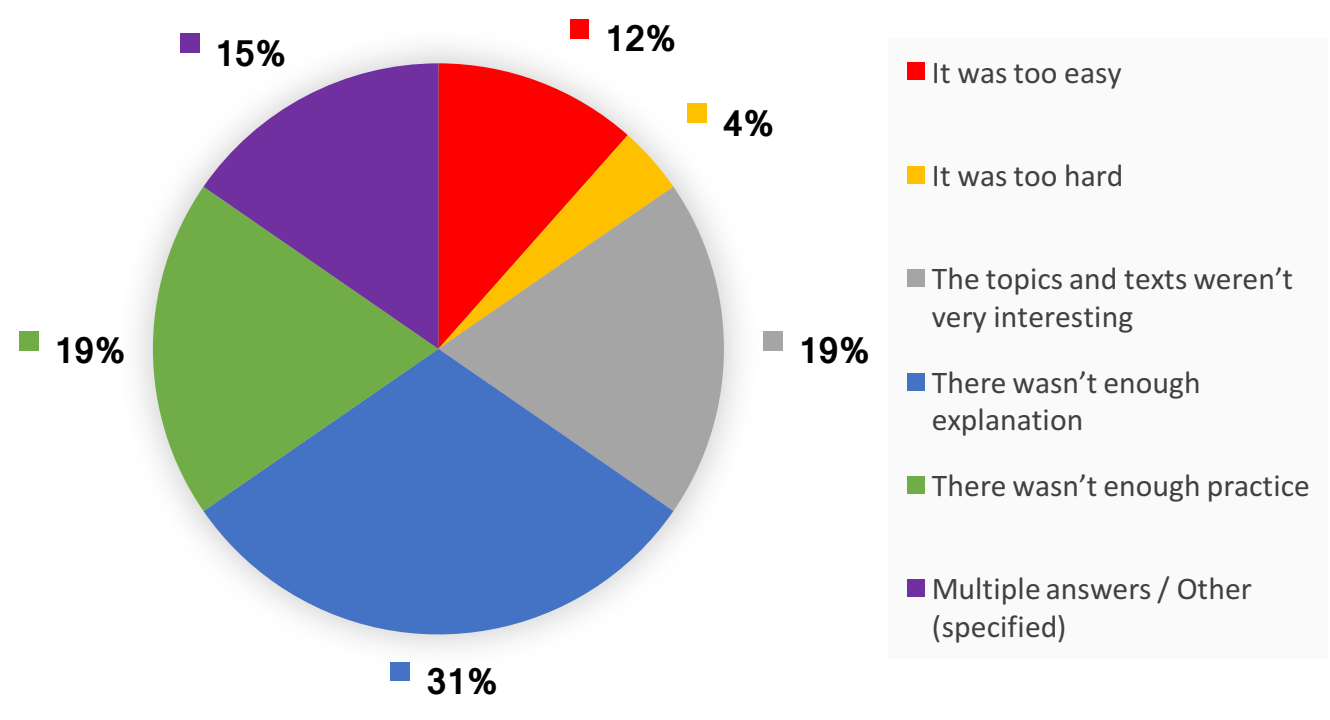

Figure 9: IEAP Teachers' Perspectives on Reasons for Students' Low Attainment

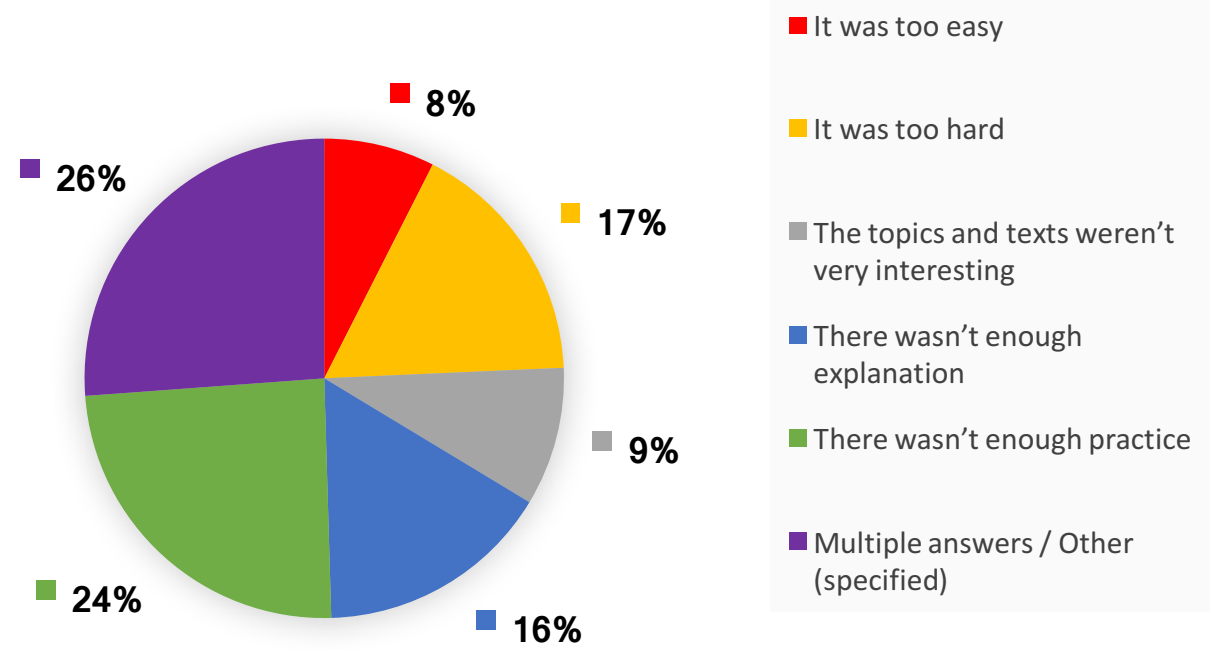

Figure 10: REAP Teachers' Perspectives on Students' Low Attainment of CLOs

\section{The Role of Textbook Exercises Towards Attainment of CLOs}

Among all the factors, textbooks exercises play a crucial role in either low or high attainment of CLOs (Mao \& Liang, 2019; Fukuta, Tamura \& Kawaguchi, 2019). In general, the teachers think that the tasks and exercises in the textbooks were suitable and they helped the students learn well. The majority of the teachers thought that the reading exercises and tasks were suitable for the students' level (66\% REAP; 73\% IEAP). The following figure 11 and 12 provide the details of the perspectives of REAP and IEAP teachers in this regard: 


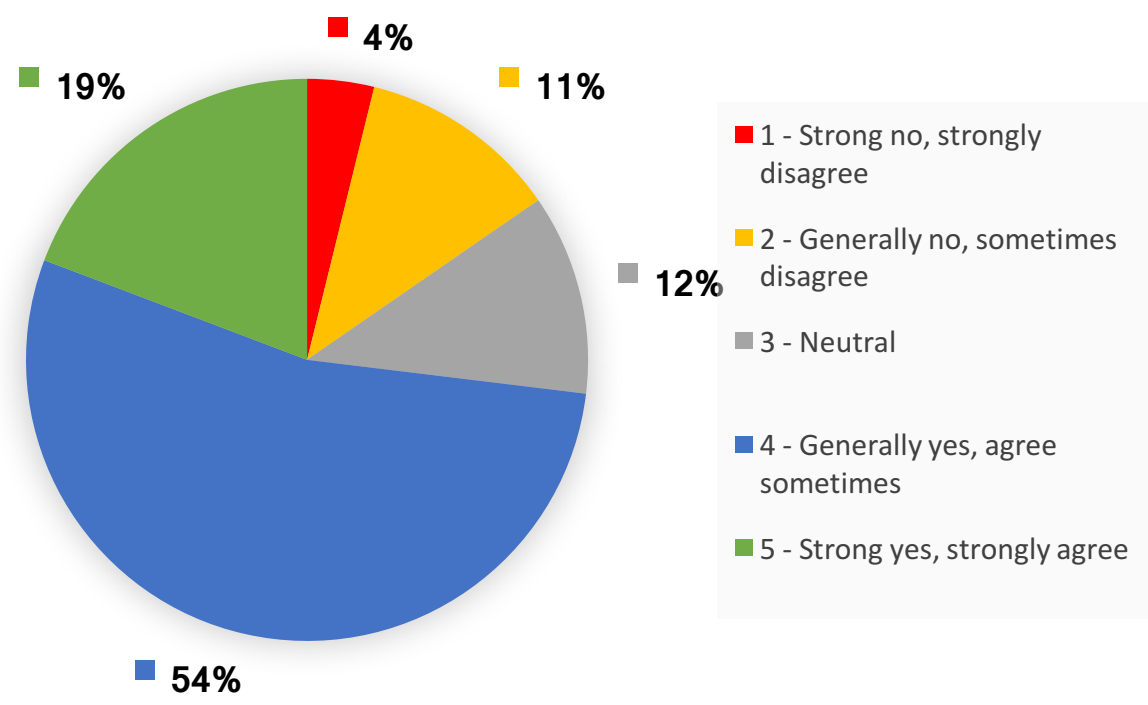

Figure 11: IEAP Teachers' Perspectives on Role of Textbook Exercises

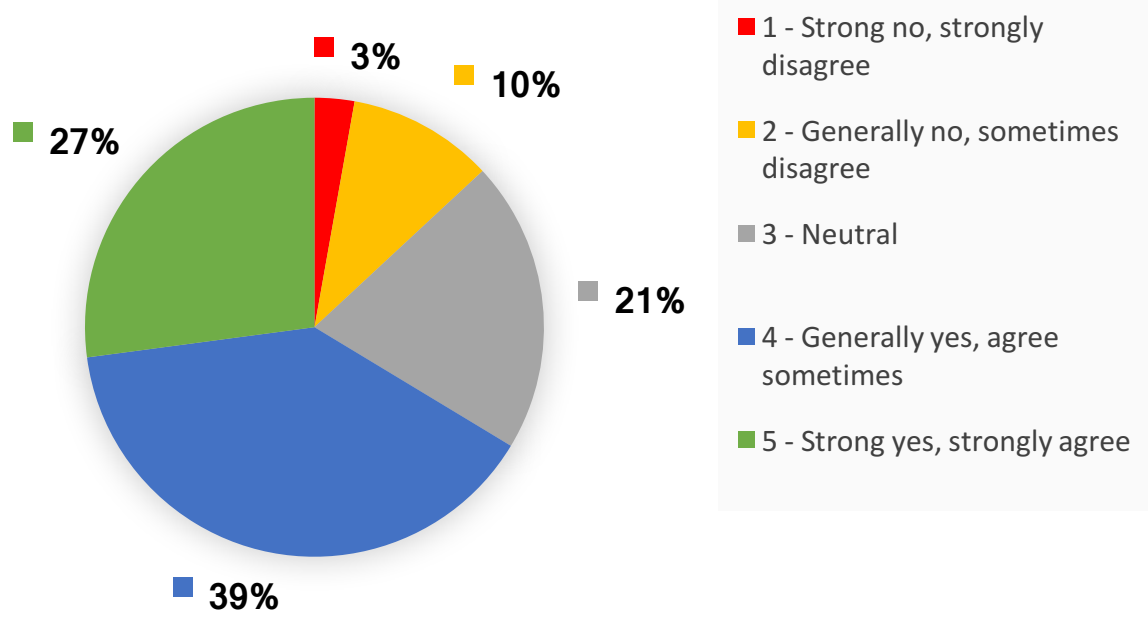

Figure 12: REAP Teachers' Perspectives on Role of Textbook Exercises

\section{Students Awareness About CLOs in General}

Just like the rest of factors, the EFL learners's awareness about CLOs is no less important (Domagała-Zyśk \& Podlewska, 2019). When asked about the importance of students' awareness about the CLOs, majority of the teachers from both REAP and IEAP groups supported the idea (77\% REAP; 61\% IEAP). The following figure 13 and 14 provide the details of the perspectives of REAP and IEAP teachers: 


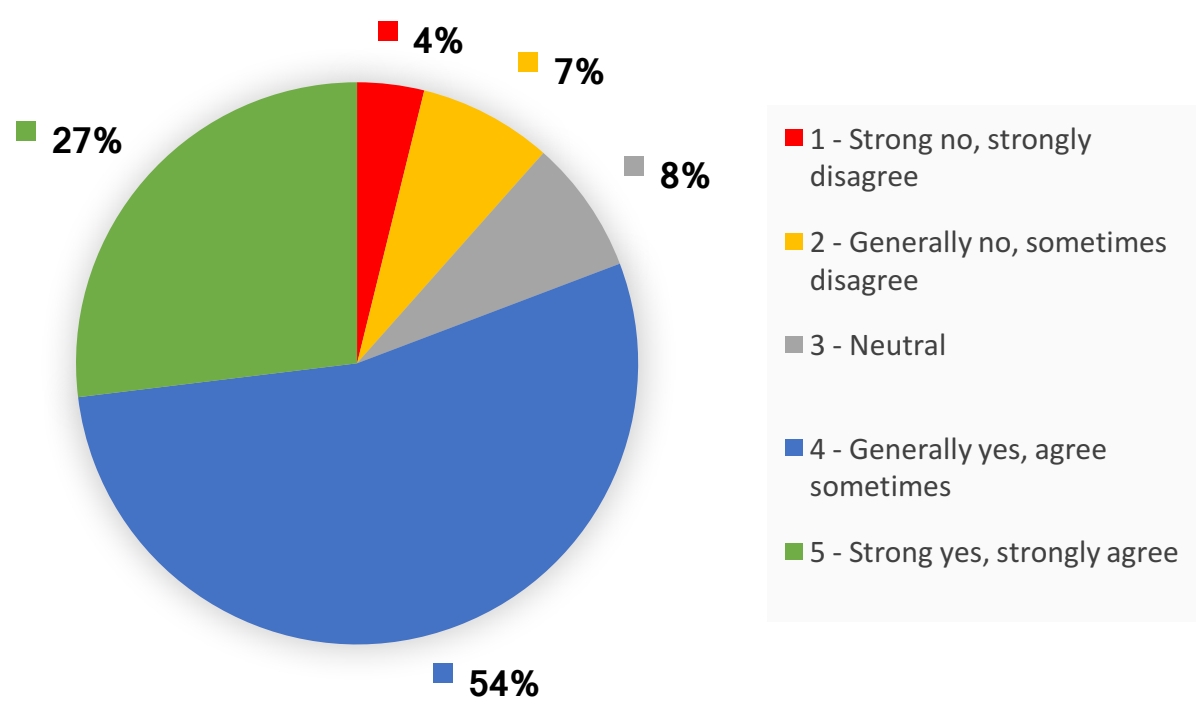

Figure 13: IEAP Teachers' Perspectives on Students' Awareness About CLOs

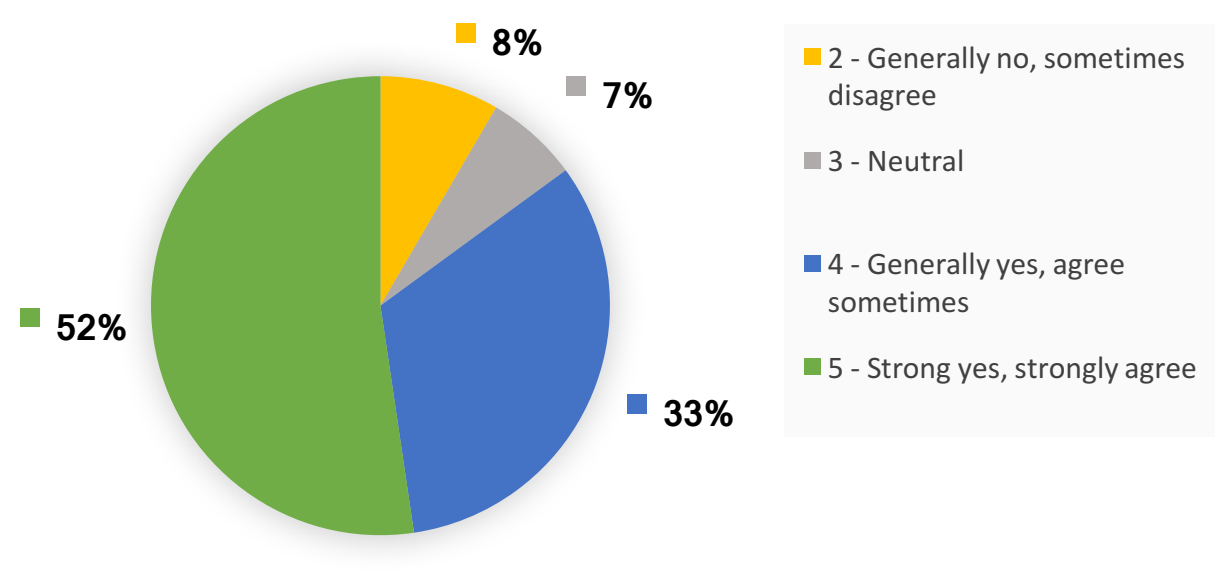

Figure 14: REAP Teachers' Perspectives About Students' CLOs Awareness

\section{THE ROLE OF SUPPLEMENTARY MATERIAL IN THE ATTAINMENT OF CLOS}

Nijakowska (2019) states that the EFL teachers preparedness in further augmented by the study material that they provide to students to achieve their study goals. This supplementary material is as important as the textbooks that are taught inside the classroom (Ra 2019; Yang \& Qian, 2019; Garcia-Pastor \& Miller, 2019). For the current study, the majority of teachers said that their students used the online materials (85\% REAP; 73\% IEAP), and that it helped them a great deal in the attainment of CLOs. According to the teachers, the students use of the supplementary material contributed towards the attainment of CLOs such as workbook exercises (54\% REAP; 31\% IEAP); or multiple online materials such as workbook exercises/tests (35\% REAP; 50\% IEAP); workbook exercises/videos/tests (35\% REAP; 30\% IEAP); workbook exercises/videos (16\% REAP; 20\% IEAP).

When asked whether the online resources were useful for their students the majority of teachers said that they were (82\% REAP; 69\% IEAP). The teachers thought that the students liked the online materials because they could practise at any time or any place (55\% REAP; $38 \%$ IEAP) or that they could practise many times by themselves (25\% REAP; $23 \%$ IEAP). 
However, while $27 \%$ of IEAP teachers said that the online materials were useful and they supported the students' learning, only $14 \%$ of REAP teachers claimed this to be the case. When asked what the students liked the least about the online materials the teachers were divided. Some said the online materials were not interesting (32\% REAP: 35\% IEAP); they were too easy (22\% REAP; $12 \%$ IEAP) or other reasons (25\% REAP; 38\% IEAP). Those teachers who said 'other' generally provided either technical or affective reasons. Some of the technical reasons were issues with login, internet connection, problems with the website, or needing book codes. Affective reasons included difficult, not interesting, too long, too easy.

\section{IMPACT ON LEARNING OUTCOMES}

Moreira (2019) advocates the proper use of CLOs to make learning more measureable. Shih and Huang (2019) also advocate the use of supplementary material to multiply the positive impact of using CLOs to gauge learners' attainment of the learning goals. During the current study, both REAP and IEAP teachers thought that the use of CLOs improved their students' language skills. However, there are some differences between REAP and IEAP teachers where some IEAP teachers are sometimes neutral about this. Both groups of teachers said that the students learnt a wide range of new vocabulary (75\% REAP; 69\% IEAP); however, it is worth noting that $31 \%$ of IEAP and $13 \%$ of REAP teachers expressed a neutral view. It might be worth investigating this further especially for the IEAP course given the higher percentage of IEAP teachers that have a neutral view about whether the students have learnt a lot of useful vocabulary. The situation is similar for reading skills where the majority of teachers said that the course has helped the students to improve their reading skills (76\% REAP; 67\% IEAP); yet, a good percentage of IEAP teachers (31\%) were neutral and 12\% thought the course did not improve their students' reading skills (compared to $16 \%$ neutral and $7 \%$ for REAP teachers). It will also be useful to examine the reasons for this with a further qualitative investigation of both IEAP and REAP teachers' views. Furthermore, the teachers thought that the course improved the students' writing skills (74\% REAP; 58\% IEAP) but again there are some IEAP teachers who are neutral (34\%, compared to 15\% REAP) about this. A large number of teachers think that the course improved the students' speaking skills (84\% REAP; 69\% IEAP) but some $31 \%$ of IEAP teachers are either neutral (19\%) or do not think the course improved the students' speaking skills (12\%). According to the teachers, the course improved the students' listening skills (83\% REAP; 77\% IEAP) and grammar skills (84\% REAP; 69\% IEAP). It is worth noting that some IEAP teachers are either neutral $(15 \%)$ or do not think that the course improved the students' grammar skills (16\%). The present research recommends that prospective researchers may further investigate this issue in an EFL context.

\section{CONCLUSION AND SUGGESTIONS FOR FUTURE RESEARCH}

The majority of the teachers think that the use of CLOs increases their students' interest in learning English (79\% REAP; 69\% IEAP) but 23\% of IEAP teachers disagree (compared to 4\% of REAP), while $8 \%$ were neutral (compared to 17\% REAP). The teachers would generally recommend its usage in other courses (85\% REAP; 61\% IEAP) with some IEAP teachers (31\%) who are neutral. The findings in this section suggest that REAP teachers tend to be slightly more satisfied with the use of CLOs than the IEAP teachers. However, the above trend needs to be interpreted cautiously having in mind that the number of REAP teachers is 107 and the number of IEAP teachers is 26. All in all, all the teachers support the use of CLOs, authenticating the fact that it makes the teaching of the course as well as its results more measurable. Keeping in view the nature of this exploratory study, more research is recommended to investigate CLOs in depth with a specific focus on framing its assessment practices. 


\section{ACKNOWLEDGEMENTS}

This is to acknowledge the support of Cambridge University Press research team as well as the Research \& Curriculum Unit of Taif University English Language Centre in the accomplishment of this article.

\section{References}

Almalki, M. (2014). A preliminary design framework for formative blended assessments in tertiary English as a foreign language (EFL) programs: an exploratory study in Saudi Arabia (Doctoral dissertation). Retrieved from The University of Melbourne library. https://minerva-access.unimelb.edu.au/handle/11343/40895

Benner, P., M. Sutphen, V. Leonard, and L. Day. (2009). Educating Nurses: A Call for Radical Transformation. San Francisco, CA: Jossey-Bass. doi:10.3928/01484834-20120402-01

Brennan, J., K. Patel, and W. Tang. (2009). Diversity in the Student Learning Experience and Time Devoted to Study: A Comparative Analysis of UK and European Evidence. Report to HEFCE by Centre for Higher Education Research and Information (CHERI), The Open University. http://www.hefce.ac.uk/media/hefce/content/pubs/2009/rd0609/rd06_09.pdf.

Dewaele, J.-M., Witney, J., Saito, K., \& Dewaele, L. (2017). Foreign language enjoyment and anxiety: Theeffect of teacher and learner variables. Language Teaching Research. https://doi.org/10.1177/1362168817692161

Eleanore Hargreaves, Dalia Elhawary \& Mohamed Mahgoub (2019) 'One girl had a different idea': children’s perspectives on learning and teaching models in the traditional classroom, Education 3-13, DOI: $\underline{10.1080 / 03004279.2019 .1586975}$

Esther Li Ling-yee (2011) Course-Specific Motivated Learning and Outcomes: The Role of the Perceived Task Value of Course-Specific Assignments, Journal of Teaching in International Business, 22:2, 107-125, DOI: $\underline{10.1080 / 08975930.2011 .615674 ~}$

Fariba Khorvash \& Ahmad Reza Lotfi | Mohammad Ali Heidari-Shahreza (Reviewing editor:) (2019) Grammatical Proficiency and Access to Extended Projections in Iranian Learners of English as a Second Language, Cogent Education, DOI: 10.1080/2331186X.2019.1592275

Gonca Yangın Ekşi, Burçak Yılmaz Yakışık, Asuman Aşık, Fatima Nur Fişne, Dorota Werbińska \& Lili Cavalheiro (2019) Language teacher trainees' sense of professional agency in practicum: cases from Turkey, Portugal and Poland, Teachers and Teaching, DOI: 10.1080/13540602.2019.1587404

Hammer, D., Piascik, P, Medina, M., Pittenger, A., Rose, R., Creekmore, F., Soltis, R., Bouldin, A., Schwarz, L., \& Steven, S. (2010). Recognition of teaching excellence. American Journal of Pharmaceutical Education, 74, 1-11.

Horwitz, E. K. (2016). Factor Structure of the Foreign Language Classroom Anxiety Scale Comment on. Psychological reports, 119(1). https://doi.org/10.1177/0033294116653368

Hui-chia Judy Shih \& Sheng-hui Cindy Huang (2019) College students' metacognitive strategy use in an EFL flipped classroom, Computer Assisted Language Learning, DOI: 10.1080/09588221.2019.1590420

H.W. Oolbekkink-Marchand, J.H. Van Driel \& N. Verloop (2014) Perspectives on teaching and regulation of learning: a comparison of secondary and university teachers, Teaching in Higher Education, 19:7, 799-811, DOI: $\underline{10.1080 / 13562517.2014 .934342}$

Iman Tohidian \& Hamid Rahimian | Tahir Nisar (Reviewing editor:) (2019) Bringing Morgan's Metaphors in Organization Contexts: An Essay Review, Cogent Business \& Management, DOI:

$\underline{10.1080 / 23311975.2019 .1587808}$

Jaewon Jane Ra (2019) Exploring the spread of English language learning in South Korea and reflections of the diversifying sociolinguistic context for future English language teaching practices, Asian Englishes, DOI: $\underline{10.1080 / 13488678.2019 .1581713}$

Joanna Nijakowska (2019) Foreign language teachers' preparedness to cater for special educational needs of learners with dyslexia: a conceptual framework, European Journal of Special Needs Education, DOI: $\underline{10.1080 / 08856257.2019 .1581401}$

Junya Fukuta, Yu Tamura \& Yusaku Kawaguchi (2019) Written languaging with indirect feedback in writing revision: is feedback always effective?, Language Awareness, DOI: 10.1080/09658416.2019.1567742 
Jyh-Chong Liang, Yen-Yuan Chen, Hong-Yuan Hsu, Tzong-Shinn Chu \& Chin-Chung Tsai (2018) The relationships between the medical learners' motivations and strategies to learning medicine and learning outcomes, Medical Education Online, 23:1, DOI: $10.1080 / 10872981.2018 .1497373$

Kevin Schoepp (2019) The state of course learning outcomes at leading universities, Studies in Higher Education, 44:4, 615-627, DOI: $10.1080 / 03075079.2017 .1392500$

Lucena, J., G. Downey, B. Jesiek, and S. Elber. (2008). “Competencies beyond Countries: The Re-organization of Engineering Education in the United States, Europe, and Latin America.” Journal of Engineering Education 97 (4): 433-447.

Maria Alfredo Moreira (2019) Project-based language learning with technology: learner collaboration in an EFL classroom in Japan, Innovation in Language Learning and Teaching, DOI: 10.1080/17501229.2019.1591419

María Dolores García-Pastor \& Ronan Miller (2019) Unveiling the needs of students who stutter in the language skills - a study on anxiety and stuttering in EFL learning, European Journal of Special Needs Education, DOI: $\underline{10.1080 / 08856257.2019 .1581400}$

Marios Hadjianastasis (2017) Learning outcomes in higher education: assumptions, positions and the views of early-career staff in the UK system, Studies in Higher Education, 42:12, 2250-2266, DOI: 10.1080/03075079.2016.1141402

McLean, H. (2018): This is the way to teach: insights from academics and students about assessment that supports learning, Assessment \& Evaluation in Higher Education, DOI: 10.1080/02602938.2018.1446508.

Mehrdad Sheybani \& Fatemeh Miri | Peter Walla (Reviewing editor:) (2019) The relationship between EFL teachers' professional identity and their critical thinking: A structural equation modeling approach, Cogent Psychology, DOI: 10.1080/23311908.2019.1592796

Mohammad Reza Ghorbani \& Seyyed Ehsan Golparvar (2019) Modeling the relationship between socioeconomic status, self-initiated, technology-enhanced language learning, and language outcome, Computer Assisted Language Learning, DOI: 10.1080/09588221.2019.1585374

Oxford, R. L. (2017). Conditions for Second Language (L2) Learning. Second and Foreign Language Education, $27-$ 41. https://doi.org/10.1007/978-3-319-02246-8 4

Sania Gul Panezai \& Liaquat Ali Channa | Hau Fai Edmond Law (Reviewing Editor) (2017) Pakistani government primary school teachers and the English textbooks of Grades 1-5: A mixed methods teachers'-led evaluation, Cogent Education, 4:1, DOI: 10.1080/2331186X.2016.1269712

Rodriguez, M. (2017). Anxiety reactions of ELF students toward in-class activities and instructors' personal characteristics and behavior. Lenguas modernas, 24, 101-112.

Raymond, J., C. Homer, R. Smith, and J. Gray. (2013). "Learning through Authentic Assessment. An Evaluation of a New Development in the Undergraduate Midwifery Curriculum.” Nurse Education in Practice 13 (5): $471-476$. doi:10.1016/j.nepr.2012.10.006.

Yanfeng Yang \& David D. Qian (2019) Promoting L2 English learners' reading proficiency through computerized dynamic assessment, Computer Assisted Language Learning, DOI: 10.1080/09588221.2019.1585882

Yu-ju Hung (2019) Bridging assessment and achievement: Repeated practice of self-assessment in college english classes in Taiwan, Assessment \& Evaluation in Higher Education, DOI: 10.1080/02602938.2019.1584783

Zhicheng Mao \& Peidong Liang (2019) The Politics of English Second Language Writing Assessment in Global Contexts, Australian Journal of Linguistics, DOI: 10.1080/07268602.2018.1559714

Zlatkin-Troitschanskaia, O., H. A. Pant, C. Kuhn, M. Toepper, and C. Lautenbach. (2017). “Assessment Practices in Higher Education and Results of the German Research Program Modeling and Measuring Competencies in Higher Education." Research \& Practice in Assessment. 